\title{
LEADING IMPLANTOLOGISTS GATHER IN MANCHESTER
}

Over 700 delegates attended the Association of Dental Implantology's (ADI's) 25th Anniversary Team Congress in Manchester in May. The theme of the Congress was 'How long do implants last? Complications, risk management and prognosis'.

International and, for the first time at an ADI conference, ADI speakers helped to answer this question, with topics covering mechanical, technical, biological and surgical complications, including diagnostic imaging, the use of pink porcelain, short implants, sinus grafting complications, IAN injury and more.
Organisers ADI President Cemal Ucer and Scientific Co-ordinator Eddie Scher invited the world's most eminent implantologists and researchers to the event including Tomas Albrektsson and Franck Renouard from Europe, German Gallucci from the USA, Professor Bragger from Switzerland and Tara Renton from the UK.

For the first time, the ADI organised a Pre-Congress session to encourage presentation of posters, cases and research findings by clinicians, technicians or postgraduate students.

\section{COLA AS BAD FOR TEETH AS CRACK}

Excessive amounts of fizzy drinks can damage \$ teeth as badly as methamphetamine (meth) or crack cocaine, according to a study published in General Dentistry. ${ }^{1}$

In the study Dr Mohamed Bassiouny, professor of restorative dentistry at the Temple University School of Dentistry in Philadelphia, says that meth, crack cocaine and fizzy drinks, whether sweetened or not, are all highly acidic and can cause similar dental problems.

The study highlights that the dentitions of individuals addicted to meth or crack cocaine can be misdiagnosed as dental caries rather than generalised dental erosion, a condition that is also associated with chronic excessive consumption of fizzy drinks. Failing to identify the causative aetiology could lead to a wrongful diagnosis that could in turn adversely affect treatment planning.

1. Bassiouny M A. Dental erosion due to abuse of illicit drugs and acidiccarbonated beverages. Gen Dent 2013; 61: 38-44

\section{HONOURS, AWARDS, APPOINTMENTS}

Plethora of prizes

Kristian Davies' BDS final year study to investigate GDPs' adherence with national recall and radiography guidelines was awarded the British Society of Dental and Maxillofacial Radiologists' prize 2013. The project was shortlisted for the Royal Society of Medicine (odontological section) President's Prize 2013 and following his oral presentation was awarded first prize for 'best research project'.

Kristian qualified from Cardiff in 2012 and has secured a place for DF2 training in the maxillofacial unit in Prince Charles Hospital, Merthyr.

Visiting professor Detroit

Dr Peter J. M. Fairbairn, west London dentist and global speaker on Alloplastic graft materials, was in February made Visiting Professor in the Department of Periodontology and Implant Dentistry of the University of Detroit Mercy School of Dentistry, Michigan USA.

King James IV professorship

The King James IV professorship of the Royal College of Surgeons of Edinburgh has been conferred on Professor Lakshman Samaranayake, the current Dean and Chair of Oral Microbiology at the Faculty of Dentistry and Tam Wah-Ching, Professor of Dental Sciences at the University of Hong Kong. The Royal College of Surgeons of Edinburgh honoured Professor Samaranayake for his outstanding contributions to surgical sciences.

\section{Practice of the month}

The dental practice Perfect 32 in Beverley, East Yorkshire, has been chosen as the first Practice of the Month by the Mouth Cancer Foundation from the UK dental practices that have signed up to the charity's Mouth Cancer Screening Accreditation Scheme.

\section{Honorary membership}

Ashok Sethi and Eddie Scher both received Honorary Membership at the Association of Dental Implantology's (ADI's) 25th Anniversary Team Congress in Manchester in May, for their outstanding contribution to the development of implantology in the UK as well as the Association over the past 25 years.

\section{GATORS MAY HOLD KEY TO TOOTH RENEWAL}

American alligators might serve as models to study tooth replacement. ${ }^{1}$

Most vertebrates renew teeth throughout their lives, whereas human teeth are naturally replaced only once despite the lingering presence of the dental lamina. Researchers studied repetitive tooth formation in alligators. Alligators have teeth with morphological traits similar to those of mammalian teeth and can replace each of their 80 teeth up to 50 times.

The authors found that each alligator tooth is a complex unit of three components in different developmental stages that are structured to facilitate replacement. At an early tooth development stage, the alligator dental lamina forms a bulge at its distal tip that houses putative, quiescent stem cells. The initiation of the tooth cycle corresponds with the dynamic expression of an array of signalling molecules implicated in tooth development. The findings might aid efforts to trigger tooth renewal in human adults who have lost teeth or to curb uncontrolled tooth development in those with supernumerary teeth.

1. Wu P, Wu X, Jiang TX et al. Specialized stem cell niche enables repetitive renewal of alligator teeth. Proc NatI Acad Sci USA 2013; 110: E2009-2018. 